\title{
Genotype-Environment-Year Interaction on Oil Antioxidants in an Olive District of Northern Italy
}

\author{
O. Failla, D. Tura and D. Bassi \\ Dipartimento di Produzione Vegetale - Università degli Studi di Milano \\ Via Celoria, 2 - 20133 Milano - Italy
}

Keywords: autoxidation stability, cultivar, Olea europea L., polyphenols, tocopherols

\begin{abstract}
A two-year survey in 18 representative groves of a north Italian olive district sampled cvs. 'Casaliva' and 'Leccino' for single-site oils. Polyphenols had a major role in determining oil autoxidation stability with respect to tocopherols, even if the higher autoxidation stability of 'Leccino' over 'Casaliva' was probably due to the more than double content in tocopherols, which was significantly affected by years. In spite of the large variations both in oil and in environmental parameters, no statistically significant model emerged for relations between antioxidants oil content and site parameters.
\end{abstract}

\section{INTRODUCTION}

Antioxidant properties represent one of the most important quality aspects of virgin olive oil, determining its shelf life and nutraceutical attributes (Castelli et al., 1999; Ryan et al., 1998). Polyphenols and tocopherols play an important role in autoxidation stability, whereas the effects of carotenoids and chlorophyll are more complex due to a shift from an antioxidant nature in the dark to a pro-oxidant activity in the light (Haila et al., 1996). Despite important research devoted to technological process improvement to keep the antioxidant level in virgin olive oil high (Malfatti et al., 2000), scant information is available about the genetic and ecophysiological causes of variation in antioxidant content in olive fruit (Bruni et al., 1994).

\section{MATERIALS AND METHODS}

The survey was conducted in 18 olive groves of 'Casaliva' and 'Leccino' cultivars in a growing district of northern Italy located on the south-west side of Lake Garda in 1997 and 1998. Five landscape units were selected for their possible interest to olive growing (Minelli, 1997): glacial tills (3 groves), outwash plains (3), linkage surfaces between tills and plains (6), contact and kame terraces (4), and high lake-coast (2). Land morphology extended from plane to steep slopes modified by artificial terraces, soils from shallow to medium in depth $(40-120 \mathrm{~cm})$, from free to rich in skeleton $(0-40 \%)$, from sandy loam to clay loam texture, from low to high in available water content (60-200 $\mathrm{mm}$ ), and elevation from 80 to $250 \mathrm{~m}$ asl. Four adult trees of average vegetative and yield performance were selected per grove and in each year oil was extracted during veraison from the fruit of a single tree after Tura et al. (2002); olive maturity index was evaluated before oil extraction after the Uceda (1983). Phenolic compounds (Angerosa et al., 1995), tocopherols (Andrikopoulos et al., 1989) and autoxidation stability (AOS: Gutierrez, 1989) were determined and the data processed with the SPSS for Windows v. 9.0 statistical package.

\section{RESULTS AND DISCUSSION}

The two-year maturity index of the harvested olives ranged from yellowish-green to black skinned fruit with the flesh not completely darkened (Table 1). In 1997 the higher air temperature and the lower rainfall recorded from September to October induced an earlier ripening than in 1998 (data not shown); note that 'Leccino' ripens three-four weeks earlier than 'Casaliva'. Wide-ranging variability values were detected for polyphenols and tocopherols, while no significant differences in oil polyphenols were detected in comparing cultivars, years and their interaction (Table 1). A significant 
difference in tocopherol was found when comparing cultivars or years, i.e. 'Leccino' oil contained more than twice the tocopherols than 'Casaliva' and in 1997 the tocopherol content was double that of the following year. The AOS showed a wide range as well and was significantly different between cultivars, with 'Leccino' showing 50\% higher values, although it was not statistically different between years. Polyphenol content was not correlated to tocopherols, neither for the single cultivar $\mathrm{x}$ year combination nor for all the data taken together. When processed by multiple regression following a step-wise method, the AOS was correlated to polyphenol and tocopherol content. According to the regression model, the AOS was mainly affected by the polyphenol levels: $1 \mathrm{ppm}$ of total polyphenols determined twice the increase in AOS than the tocopherol's (AOS $=6.1+$ $0.54 *$ polyphenols +0.24 tocopherols; $r=0.73$ ); the cultivar difference in AOS was consequently due to tocopherols (Figure 1). Comparing polyphenols and AOS levels with the fruit maturity index showed no significant cultivar correlation in 1997. A significantly high correlation between maturity index and polyphenol levels was detected in 'Leccino' oils in 1998. A similar trend was also found for 'Casaliva' oils, even if the significance of the correlation was above the 5\% level (Figure 2). While tocopherol levels were related to fruit maturity index when the two-year data were pooled, no relations emerged within the same cultivar x year combination (Figure 3 ). Site and soils descriptors were unable to explain even part of the large variations in fruit maturity and autoxidation properties.

\section{CONCLUSIONS}

Our two-year data indicate an adequate antioxidant properties of oils, as also detected by Poiana et al. (1999), although marked variations in polyphenols, tocopherols and autoxidation stability were detected in our survey. Polyphenols played a major role in determining autoxidation stability with respect to tocopherols, even if the higher autoxidation stability of cv. 'Leccino' oils was in all liklelihood due to their having double the tocopherol content with respect to 'Casaliva' oils. Years had a significant effect on tocopherols and a minor effect on autoxidation stability. A positive relation between fruit maturity index and polyphenol content was detected, particularly in 'Leccino' for one of the two years. In spite of the large variations both in oil and in environmental parameters, no statistically significant model emerged for relations between antioxidants and site parameters. Therefore, the causes of the marked variability in fruit maturity and antioxidant properties require further investigation. Plant physiological status and possible cultivar clonal variations should be taken into greater account.

\section{ACKNOWLEDGEMENTS}

Research funded by EU Commission, Reg. CE 2430/97 in cooperation with the Agriculture Department of Lombardy Region, Italy. We thank R. Minelli, S. Pedò and A. Serraiocco for their precious collaboration.

\section{Literature Cited}

Andrikopoulos, N., Hassapidou, M. and Manoukas, A. 1989. The tocopherol content of Greek olive oil. J. Sci. Food Agric. 46: 503-509.

Angerosa, F., D'Alessandro, N., Konstantinou, P. and Di Giacinto, L. 1995. GC-MS evaluation of phenolic compounds in virgin olive oil. J. Agric Food Chem 43: 1802-7.

Bruni, U., Cortesi, N. and Fiorino, P. 1994. Influenza di tecniche agronomiche, cultivar e zone di origine su caratteri dell'olio vergine di oliva e livelli di alcuni suoi componenti «minori». Olivae 53: 28-34.

Castelli, F., Muzzalupo, I., Saija, A., Tomaino, A. and Uccella, N. 1999. I biofenoli nelle olive e nell'olio per il benessere dell'uomo. Olivo \& Olio 9: 48-61.

Gutierrez, F. 1989. Determination of oxidative stability in virgin olive oil: comparison between active oxygen method and Rancimat method. Grasas y Aceites 40: 1-5.

Haila, K.M., Lievonen, S.M. and Heinonen, M.I. 1996. Effects of lutein, lycopene, annatto and $\gamma$-tocoferol on autoxidation of triglycerides. J. Agric. Food Chem. 44: 
2096-2100.

Malfatti, A., Ranalli, A. and Contento, S. 2000. Qualità e genuità degli oli vergini di oliva di pressione estratti con Cytolase 0. Olivo \& Olio 7/8: 32-51.

Minelli, R. 1997. I suoli dell' area morenica gardesana settore bresciano. ERSAL, Milano.

Poiana, M., Giuffrè, A.M., Sicari, V., Mincione, B., Marca, F., Penitenti, M. and Zanelli, S. 1999. Ricerche sugli oli di oliva nazionali. Aspetti merceologici della produzione degli oli della Riviera del Garda Bresciano e del Sebino. Olivo \& Olio 7/8: 35-47.

Ryan, D., Robards, K. and Lavee, S. 1998. Valutazione della qualità nell'olio d'oliva. Olivae 72: 23-41.

Tura, D., Failla, O., Bassi, D. and Serraiocco, A. 2002. Sensory and chemical analisys of monovarietal olive oils from Garda lake (northern Italy). Fourth international symposium on olive growing. Acta Hort. in this volume.

Uceda, M. 1983. Factores que influyen en la calidad del aceite de oliva. Simp. Expoliva 83, Jaen (E).

\section{$\underline{\text { Tables }}$}

Table 1. Maturity index, total polyphenols ( $\mathrm{ppm}$ of resorcinol), total tocopherols (ppm $\alpha+\delta+\gamma$ tocopherol) and autoxidation stability (AOS): main frequency distribution parameters, cultivar and year comparisons.

\begin{tabular}{llllllllll}
\hline & Total samples & \multicolumn{3}{c}{ Cultivar $^{1}$} & Year $^{1}$ \\
\hline & No. & Mean & Sd & Min & Max & Casaliva & Leccino & 1997 & 1998 \\
\hline Maturity index & 37 & 3.4 & 1.1 & 1.4 & 5.1 & $2.7 \mathrm{a}$ & $4.1 \mathrm{~b}$ & $4.1 \mathrm{a}$ & $2.8 \mathrm{~b}$ \\
Polyphenols (ppm) & 36 & 143 & 83 & 24 & 369 & $154 \mathrm{a}$ & $130 \mathrm{a}$ & $120 \mathrm{a}$ & $161 \mathrm{a}$ \\
Tocopherols (ppm) & 37 & 161 & 96 & 42 & 416 & $97 \mathrm{a}$ & $228 \mathrm{~b}$ & $217 \mathrm{a}$ & $114 \mathrm{~b}$ \\
AOS (days/kg) & 37 & 120 & 58 & 40 & 254 & $94 \mathrm{a}$ & $146 \mathrm{~b}$ & $103 \mathrm{a}$ & $134 \mathrm{a}$ \\
\hline
\end{tabular}

${ }^{1}$ In rows: values followed by the same letter are not statistical different for $\mathrm{P} \leq 5 \%$.

\section{Figures}

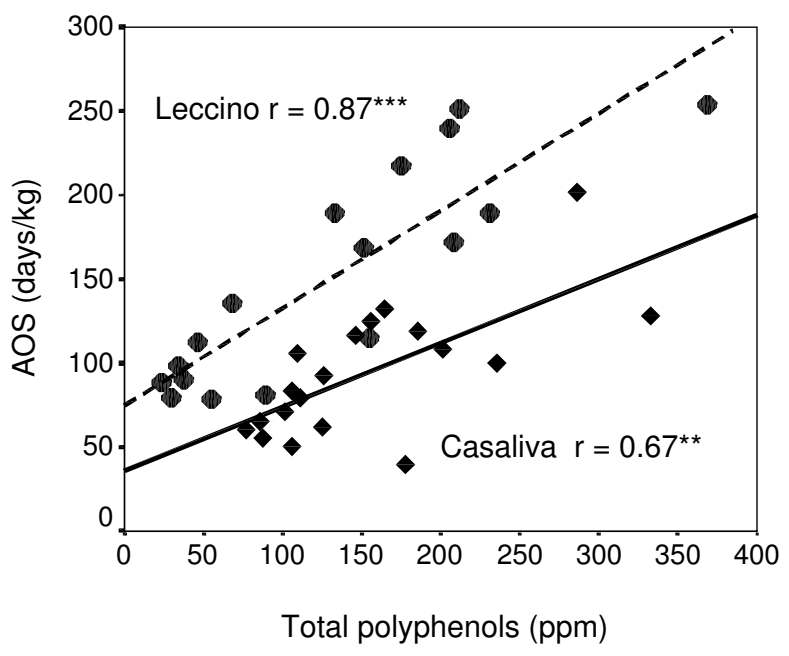

Fig. 1. Regression between polyphenols and antioxidant stability in mono site oils (1997 and 1998). 

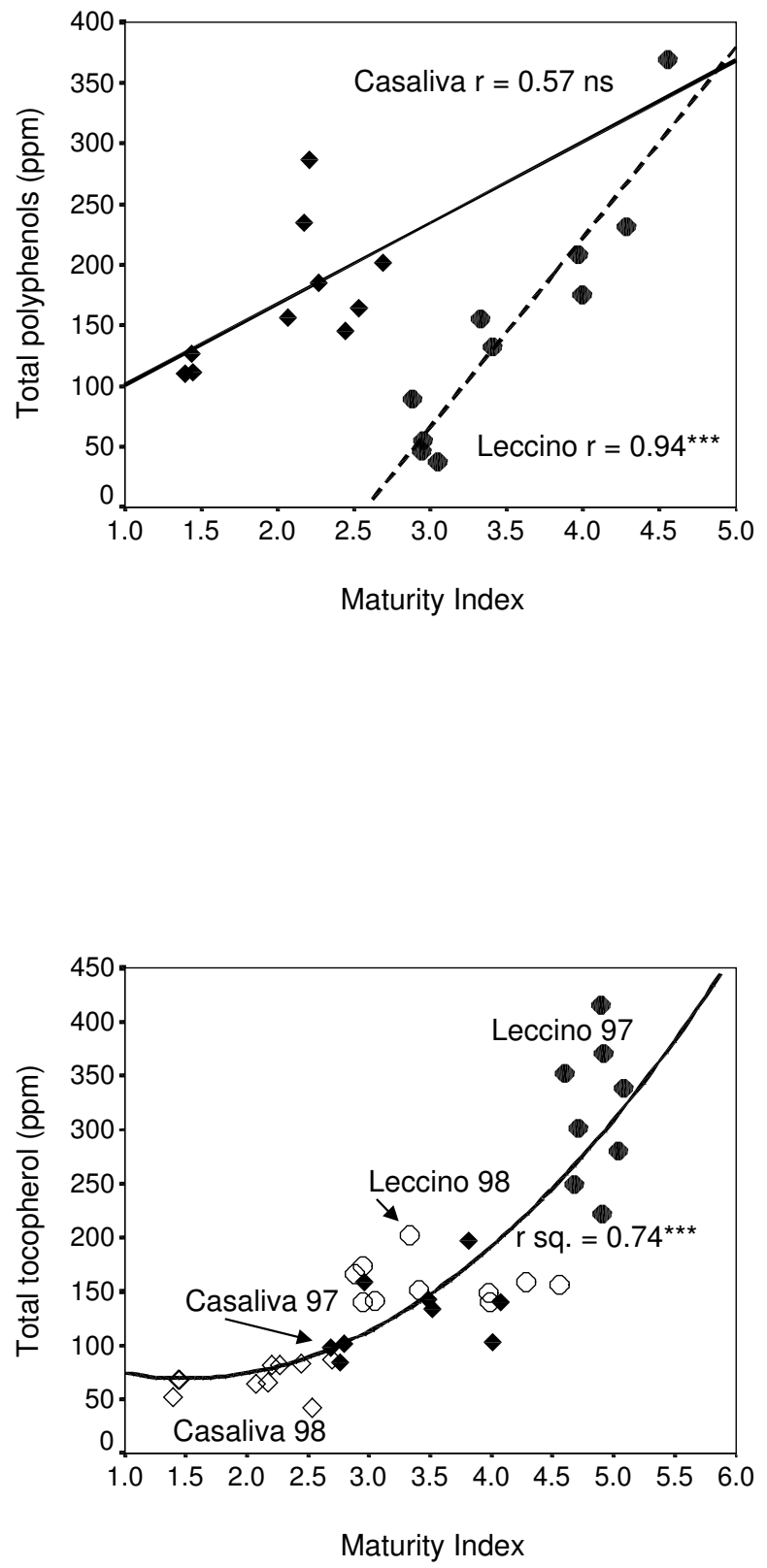

Fig. 2. Regression between olive maturity index and polyphenols (1998).
Fig. 3. Regression between olive maturity index and tocopherols (1997 and 1998). 


\title{
GENOTYPE-ENVIRONMENT-YEAR INTERACTION ON OIL ANTIOXIDANTS IN AN OLIVE GROWING DISTRICT IN NORTHERN ITALY
}

\author{
O. Failla, D. Tura, S. Pedò and D. Bassi \\ Dipartimento di Produzione Vegetale \\ Università degli Studi -Via Celoria, 2 - 20133 Milano, Italy
}

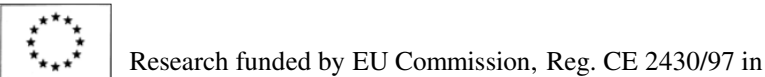 cooperation with the Agriculture Department of Lombardy Region, Italy.

A two year survey was conducted in an olive growing district of northern Italy, 18 representative orchards were chosen. 'Casaliva' and 'Leccino' cultivars were sampled to obtain mono site oils.

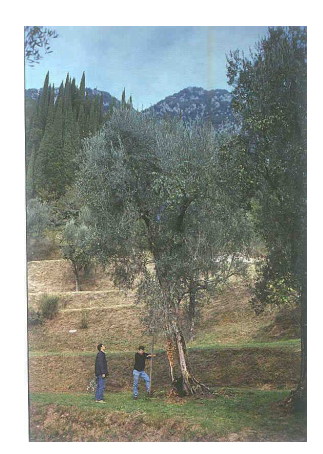

High lake-coast

\begin{tabular}{|c|c|}
\hline Landscape units & Site $\mathbf{n}^{\circ} \quad$ Site characteristics \\
\hline $\begin{array}{l}\text { End and lateral } \\
\text { moraine ridges }\end{array}$ & $\begin{array}{l}3 \text { Olive orchards are on slopes modified by artificial terraces. Soils are } \\
\text { shallow }(40-60 \mathrm{~cm}) \text {, rich in skeleton }(30-40 \%) \text {, sandy loam textured, } \\
\text { low in } \mathrm{AWC}^{1}(60-80 \mathrm{~mm}) \text {. Site altitude ranges from } 140 \text { to } 215 \mathrm{~m} \text { a.s.l. }\end{array}$ \\
\hline Outwash plains & $\begin{array}{l}3 \text { Lands are plane or sub plane. Soils are from shallow to medium in } \\
\text { depth }(60-120 \mathrm{~cm}) \text {, rich in skeleton }(20-30 \%) \text {, clay-loam textured, } \\
\text { medium or high in } \mathrm{AWC}^{1}(120-200 \mathrm{~mm}) \text {. Site altitude is around } 140 \mathrm{~m} \\
\text { a.s.l. }\end{array}$ \\
\hline $\begin{array}{l}\text { Linkage surfaces } \\
\text { between moraines } \\
\text { and plains }\end{array}$ & $\begin{array}{l}6 \text { Lands are slightly sloped }(3-5 \%) \text {. Soils are from shallow to medium in } \\
\text { depth }(40-120 \mathrm{~cm}) \text {, from free to rich in skeleton }(0-40 \%) \text {, from sandy- } \\
\text { loam to clay-loam textured, from low to high in } \mathrm{AWC}^{1}(60-120 \mathrm{~mm}) \text {. } \\
\text { Site altitude ranges from } 80 \text { to } 180 \mathrm{~m} \text { a.s.1. }\end{array}$ \\
\hline $\begin{array}{l}\text { Contact and kame } \\
\text { terraces }\end{array}$ & $\begin{array}{l}4 \text { Lands are plane or sub plane. Soils are from shallow to medium in } \\
\text { depth }(60-120 \mathrm{~cm}) \text {, rich in skeleton }(20-30 \%) \text {, sandy-loam textured, } \\
\text { from medium to high in } \mathrm{AWC}^{1}(80-120 \mathrm{~mm}) \text {. Site altitude ranges from } \\
160 \text { to } 250 \mathrm{~m} \text { a.s.1. }\end{array}$ \\
\hline High lake-coasts & $\begin{array}{l}2 \text { Olive orchards are on steep slopes modified by artificial terraces. Soils } \\
\text { and sites characterisation is still in progress. }\end{array}$ \\
\hline
\end{tabular}

$1 \mathrm{AWC}=$ available water content

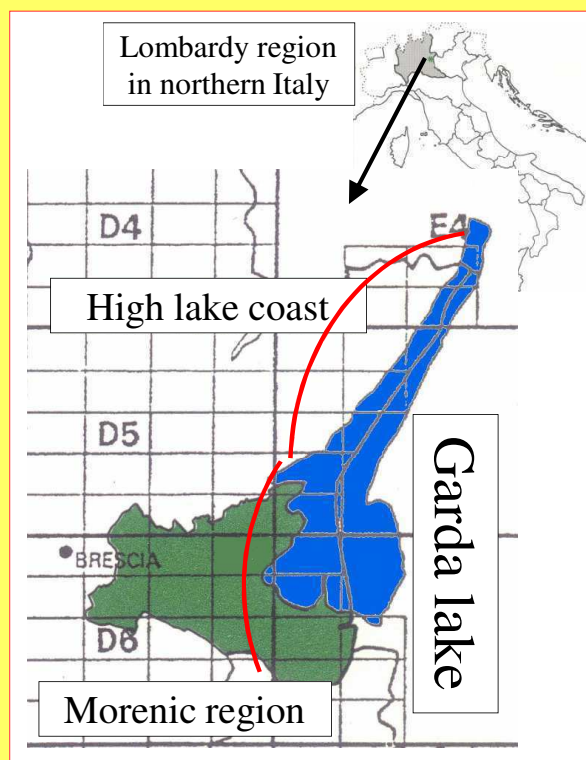

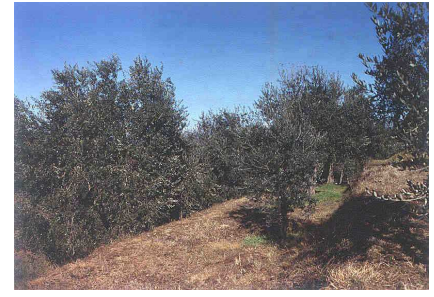

Moraine ridges

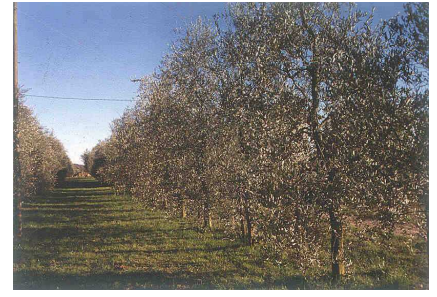

Linkage surfaces

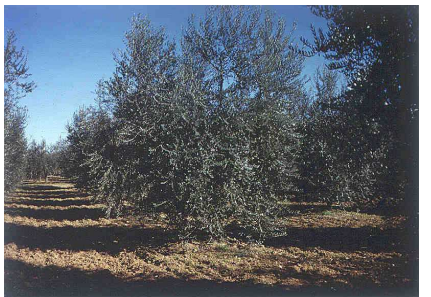

Outwash plains

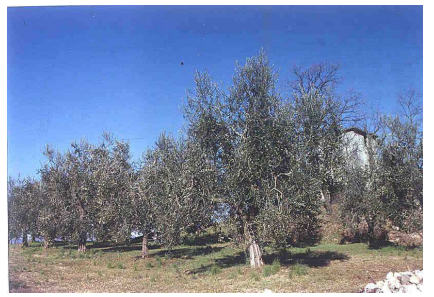

Terraces

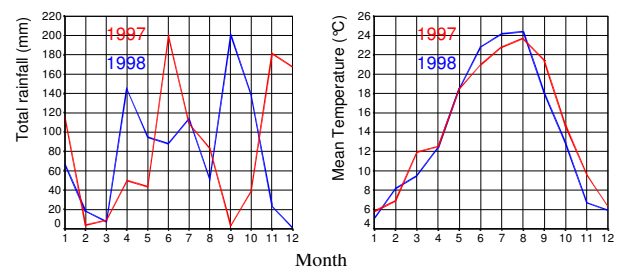

In 1998, September and October were cooler and more rainy than 1987 , this induced a later fruit ripening

In 1998 a significant

high correlation

between maturity index and polyphenol levels was detected in 'Leccino' oils. A similar trend was seen also for

'Casaliva' oils, even if the significance of the correlation was above the $5 \%$ level.
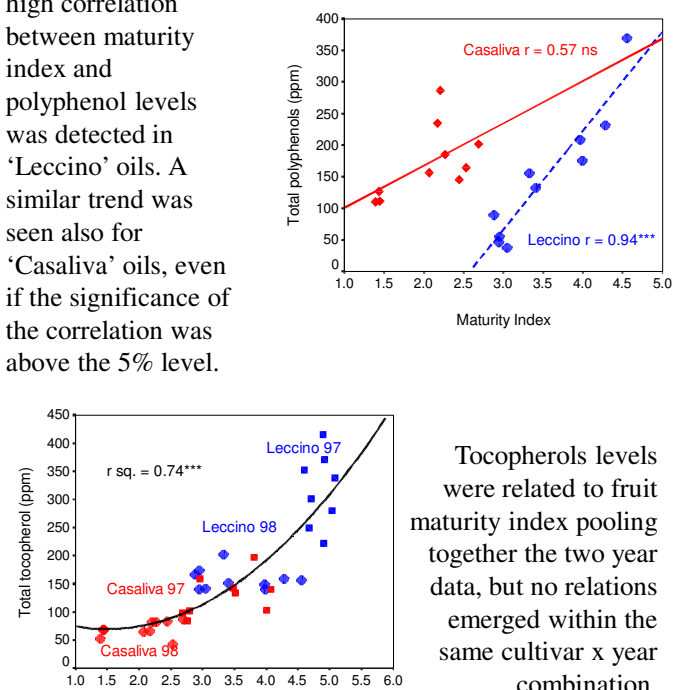

Tocopherols levels were related to fruit maturity index pooling together the two year data, but no relations emerged within the same cultivar $\mathrm{x}$ year combination.

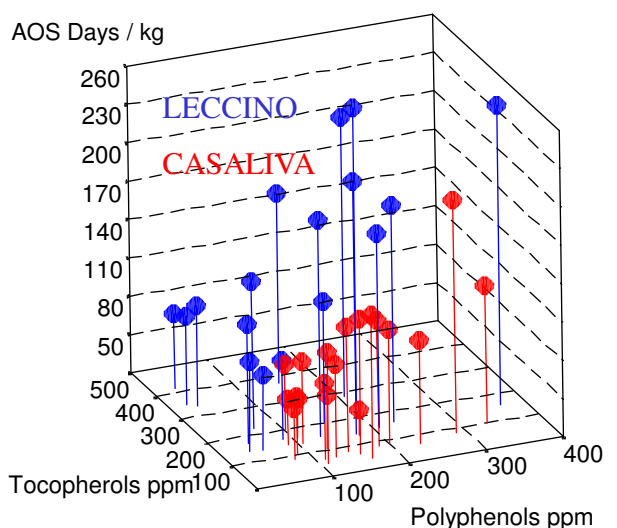

- AOS was correlated to polyphenol and tocopherol content by multiple regression, following a step wise method.

- AOS was mainly affected by the polyphenol levels: one ppm of total polyphenols determined an increase in AOS twice than tocopherol.

-AOS showed an ample variability range as well was significantly different between cultivars, with 'Leccino' showing 50\% higher values.

- The cultivar difference in AOS were due to tocopherols

$\mathrm{AOS}=6.1+0.54 *$ Total polyphenols +0.24 Total tocopherols $; \mathrm{r}=0.73 ; \mathrm{r}^{2}=0.53$

\section{CONCLUSION}

- Polyphenols had a major role in determining oil antioxidant stability in respect to tocopherols.

- The higher antioxidant stability of 'Leccino' vs. 'Casaliva was likely due to the more than double content in tocopherols.

-Tocopherols were significantly affected by year.

- In spite of the large variations both in oil and in environmental parameters, no statistically significant model emerged for relations among antioxidants and site parameters (i.e. landscape unit, altitude, soil depth, texture, available water content). 